\title{
G-Protein-Coupled Receptor Signaling in Cilia
}

\author{
Kirk Mykytyn ${ }^{1,2}$ and Candice Askwith ${ }^{2,3}$ \\ ${ }^{1}$ Department of Biological Chemistry and Pharmacology, The Ohio State University, Ohio 43210 \\ ${ }^{2}$ Neuroscience Research Institute, The Ohio State University, Ohio 43210 \\ ${ }^{3}$ Department of Neuroscience, The Ohio State University, Ohio 43210 \\ Correspondence: mykytyn.1@osu.edu
}

G-protein-coupled receptors (GPCRs) are the largest and most versatile family of signaling receptors in humans. They respond to diverse external signals, such as photons, proteins, peptides, chemicals, hormones, lipids, and sugars, and mediate a myriad of functions in the human body. Signaling through GPCRs can be optimized by enriching receptors and downstream effectors in discrete cellular domains. Many GPCRs have been found to be selectively targeted to cilia on numerous mammalian cell types. Moreover, investigations into the pathophysiology of human ciliopathies have implicated GPCR ciliary signaling in a number of developmental and cellular pathways. Thus, cilia are now appreciated as an increasingly important nexus for GPCR signaling. Yet, we are just beginning to understand the precise signaling pathways mediated by most ciliary GPCRs and how they impact cellular function and mammalian physiology.

t is estimated that the human genome encodes approximately $950 \mathrm{G}$-protein-coupled receptors (GPCRs), of which 500 correspond to odorant or taste receptors (Takeda et al. 2002). Approximately 150 of the remaining 450 GPCRs have no known natural ligand and so are referred to as orphan GPCRs (Tang et al. 2012). GPCRs represent the largest group of therapeutic drug targets, with more than a third of all drugs acting on GPCRs (Rask-Andersen et al. 2011). Because of the functional diversity of GPCRs, there is little conservation of amino acid sequence across the GPCR superfamily. Yet, all GPCRs share a common structure: an extracellular amino terminus, seven transmembrane domains, and an intracellular carboxyl terminus.
In canonical GPCR signaling at the plasma membrane, agonist binding to a receptor causes a change in receptor conformation and results in activation of heterotrimeric GTPbinding proteins (G proteins) (Fig. 1A) (Shenoy and Lefkowitz 2011). G proteins consist of three associated protein subunits: $\alpha, \beta$, and $\gamma$. G proteins are classified based on the nature of their $\alpha$-subunits and there are 16 known $\alpha$-subunits that are functionally categorized into four subfamilies: $\mathrm{G} \alpha_{\mathrm{s}}, \mathrm{G} \alpha_{\mathrm{i}}, \mathrm{G} \alpha_{\mathrm{q}}$, and $\mathrm{G} \alpha_{12}$. When inactive, the $\alpha$-subunit is bound to GDP and a $\beta \gamma$-complex to form a trimeric protein complex (Fig. 1A). On agonist binding, the receptor facilitates GDP release, GTP binding to the $\alpha$-subunit, and dissociation of the $\alpha$-subunit from the $\beta \gamma$ -

Editors: Wallace Marshall and Renata Basto

Additional Perspectives on Cilia available at www.cshperspectives.org

Copyright (C) 2017 Cold Spring Harbor Laboratory Press; all rights reserved; doi: 10.1101/cshperspect.a028183

Cite this article as Cold Spring Harb Perspect Biol 2017;9:a028183 
K. Mykytyn and C. Askwith
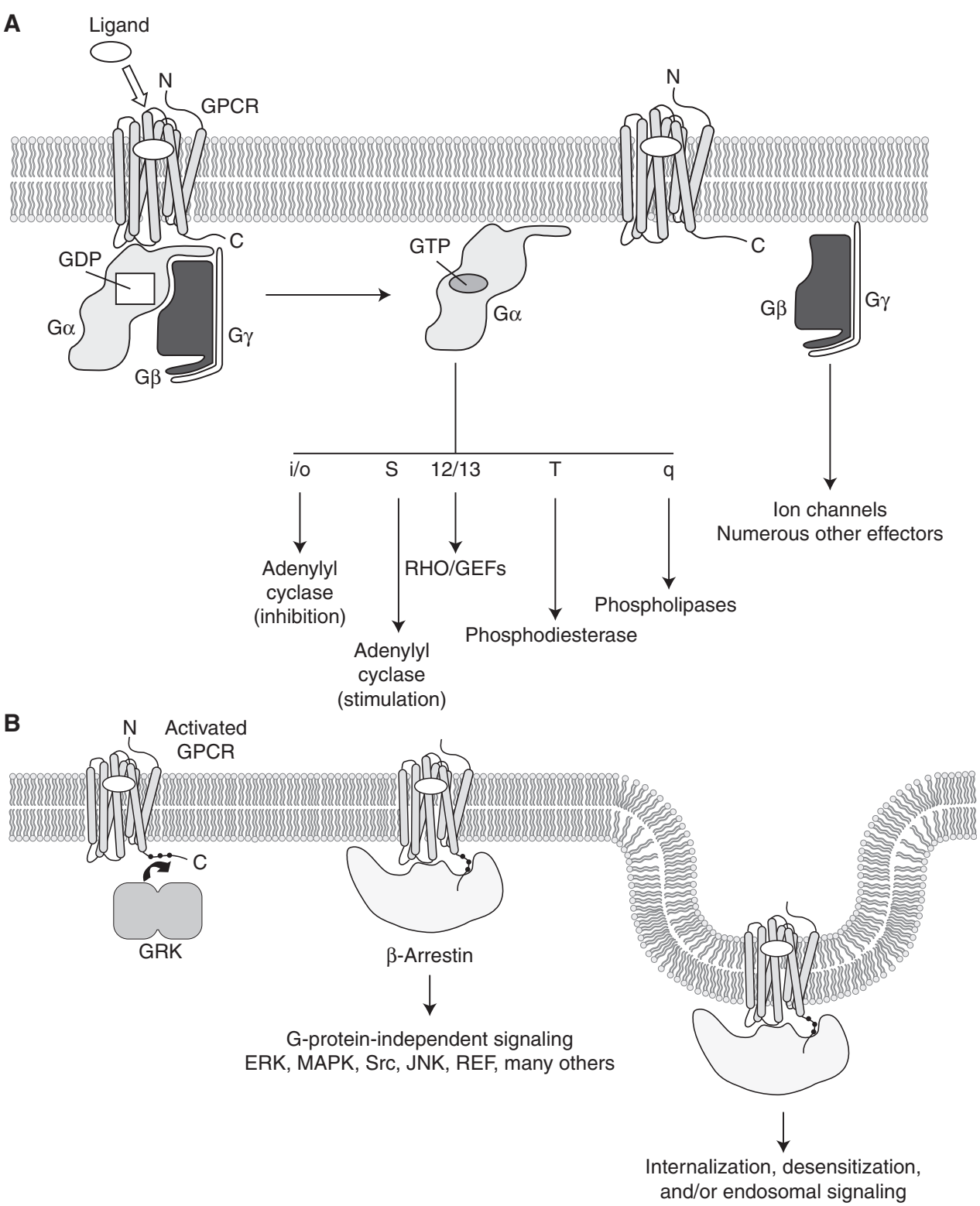

Figure 1. Overview of G-protein-coupled receptor (GPCR) signaling at the plasma membrane. (A) Ligand binding to a GPCR facilitates GDP release from the G-protein $\alpha$-subunit and stimulates GTP binding to the $\alpha$-subunit, which leads to dissociation of the $\alpha$-subunit from the $\beta \gamma$-complex. Both the $\alpha$-subunit and $\beta \gamma$ complex can then regulate various intracellular effectors. $(B)$ Activated GPCRs are phosphorylated at specific sites on their intracellular domains predominantly by G-protein-coupled receptor kinases (GRKs). Phosphorylated receptors are targets for the recruitment of $\beta$-arrestins, which prevent further G-protein activation and mediate internalization of receptors by promoting clathrin-mediated endocytosis. $\beta$-Arrestins bind to numerous intracellular signaling proteins and can act as signal transducers independently of G-protein coupling. In some cases, GPCR signaling can be sustained or enhanced on endocytosis. 
Ciliary GPCR Signaling

complex (Fig. 1A). Both the $\alpha$-subunit and $\beta \gamma$-complex can then regulate various intracellular effectors (e.g., adenylyl cyclases by the $\alpha$-subunit and potassium channels by the $\beta \gamma$ complex).

Activated GPCRs are then phosphorylated at specific sites on their intracellular domains predominantly by G-protein-coupled receptor kinases (GRKs) (Fig. 1B) (Marchese et al. 2008), but also other kinases such as protein kinase $A$ (PKA) or protein kinase C (PKC) (Kelly et al. 2008). Once phosphorylated, the receptors become targets for the recruitment and binding of scaffolding proteins, termed $\beta$-arrestins, which prevent further $\mathrm{G}$-protein activation and mediate internalization of receptors by promoting clathrin-mediated endocytosis (Fig. 1B) (Shenoy and Lefkowitz 2011). This process is known as homologous desensitization. Although internalization of GPCRs is generally associated with a decrease in signaling, in some cases receptor signaling can be sustained or enhanced on endocytosis (Sorkin and von Zastrow 2009; McMahon and Boucrot 2011). In addition, $\beta$-arrestins bind to numerous intracellular signaling proteins, including Src, ERK1/2, p38, and PI3K, and can act as signal transducers independent of G-protein coupling (DeFea 2011; Shukla et al. 2011). There are two $\beta$-arrestin isoforms ( 1 and 2 ) that are expressed ubiquitously and regulate most GPCRs.

There is an ever-expanding list of GPCRs that are enriched in cilia on a variety of cell types (Table 1; Fig. 2). Numerous GPCR effector molecules have also been localized to cilia (Fig. 2) (Hilgendorf et al. 2016), suggesting that cilia mediate signaling of a diverse set of GPCRs. Importantly, ciliopathies are associated with alterations in GPCR signaling. In this review, we will focus on mammalian cilia-mediated GPCR signaling transduction pathways. We will begin with a brief account of the well-described signaling pathways mediated by the prototypical ciliary GPCRs, odorant receptors, and opsins. Then we will discuss more recently described examples of GPCR ciliary signaling with a focus on the potential functional impacts of cilia on GPCR signaling.

\section{OLFACTORY RECEPTOR SIGNALING}

Ciliopathies can be associated with deficits in olfaction (Kulaga et al. 2004; Iannaccone et al. 2005; McEwen et al. 2007). Mammalian olfaction is mediated by olfactory sensory neurons (OSNs) that project from the olfactory bulb in the brain to the olfactory epithelium located in the nasal cavity (Fig. 3A). OSNs are bipolar neurons with a single axon that projects distally to the olfactory bulb and a single dendrite that projects apically to the olfactory epithelium. At the apical end of the OSN, the dendritic tip is enlarged to form a dendritic knob from which 10 to 30 nonmotile $9+2$ cilia project (Menco $1980,1997)$. These olfactory cilia range from 50 to $60 \mu \mathrm{m}$ in length and extend into the olfactory mucus where they are directly exposed to odorants (Jenkins et al. 2009). There are two important consequences of the ciliary structure. First, the presence of numerous cilia increases the surface area that is exposed to the external environment by about 40 times and enhances our ability to detect odorants (Menco 1992). Second, the small diameter of the distal ends of these cilia $(\sim 0.1 \mu \mathrm{m})$ leads to a large ratio of membrane surface area to cytoplasmic volume (Menco 1980), allowing a small signal to generate a large effect.

The molecular elements required for olfactory transduction are concentrated within the ciliary compartment (Fig. 3B). Olfaction begins with binding of an odorant to an olfactory receptor (OR) on the ciliary membrane. In rodents, each OSN predominantly expresses one of approximately 1000 ORs (Ressler et al. 1993; Vassar et al. 1993), which triggers the activation of the heterotrimeric stimulatory $G$ protein comprising $\mathrm{G} \alpha_{\mathrm{olf}}, \beta_{1}$, and $\gamma_{13}$ (Jones and Reed 1989; Kerr et al. 2008; Li et al. 2013). $\mathrm{G} \alpha_{\text {olf }}$ then activates type 3 adenylyl cyclase (AC3), which increases cAMP levels within the cilium (Bakalyar and Reed 1990). The cAMP then binds to and activates cyclic-nucleotide-gated $(\mathrm{CNG})$ channels on the ciliary membrane, allowing the entry of calcium ions and depolarizing the membrane potential. Increased ciliary $\mathrm{Ca}^{2+}$ levels leads to activation and opening of $\mathrm{Ca}^{2+}$-gated chloride channels, 
K. Mykytyn and C. Askwith

\begin{tabular}{|c|c|c|}
\hline GPCR & Cell type & References \\
\hline$\beta 2$-adrenergic receptor $(\beta 2 \mathrm{AR})$ & Neurons & Yao et al. 2015 \\
\hline Bile acid receptor (TGR5) & Cholangiocytes & Keitel et al. 2010; Masyuk et al. 2013 \\
\hline Bitter taste receptors (T2R) & Airway epithelial cells & Shah et al. 2009 \\
\hline Dopamine receptor 1 (D1) & Neurons & Domire et al. 2011 \\
\hline Dopamine receptor 5 (D5) & $\begin{array}{l}\text { Vascular endothelial cells, } \\
\text { renal epithelial cells }\end{array}$ & $\begin{array}{l}\text { Abdul-Majeed and Nauli 2011; } \\
\text { Jin et al. 2014b }\end{array}$ \\
\hline Galanin receptor 3 (GALR3) & Neurons & Loktev and Jackson 2013 \\
\hline GPR83 & Neurons & Loktev and Jackson 2013 \\
\hline GPR161 & $\begin{array}{l}\text { Neurons, mouse embryonic } \\
\text { fibroblasts }\end{array}$ & Mukhopadhyay et al. 2013 \\
\hline GPR175 & $\begin{array}{l}\text { Mouse embryonic } \\
\text { fibroblasts }\end{array}$ & Singh et al. 2015 \\
\hline Kisspeptin receptor 1 (KISS1R) & Neurons & Koemeter-Cox et al. 2014 \\
\hline $\begin{array}{l}\text { Melanin-concentrating hormone } \\
\text { receptor } 1 \text { (MCHR } 1)\end{array}$ & Neurons & Berbari et al. 2008 \\
\hline $\begin{array}{l}\text { Muscarinic acetylcholine receptor } 3 \\
\text { (M3R) }\end{array}$ & Olfactory sensory neurons & Jiang et al. 2015 \\
\hline Neuropeptide Y receptor 2 (NPY2R) & Neurons & Loktev and Jackson 2013 \\
\hline Neuropeptide Y receptor 5 (NPY5R) & Neurons & Loktev and Jackson 2013 \\
\hline $\begin{array}{l}\text { Prolactin-releasing hormone } \\
\text { receptor (PRLHR) }\end{array}$ & Glial cells & Omori et al. 2015 \\
\hline Prostaglandin E receptor 4 (EP4) & $\begin{array}{l}\text { Human retinal pigment } \\
\text { epithelial cells }\end{array}$ & Jin et al. 2014a \\
\hline $\begin{array}{l}\text { Pyroglutamylated RFamide peptide } \\
\text { receptor (QRFPR) }\end{array}$ & Neurons & Loktev and Jackson 2013 \\
\hline Serotonin receptor 6 (HTR6) & Neurons & Brailov et al. 2000 \\
\hline Smoothened (SMO) & Fibroblasts, nodal cells & \\
\hline Somatostatin receptor 3 (SSTR3) & Neurons & Handel et al. 1999 \\
\hline $\begin{array}{l}\text { Trace amine-associated receptor } 1 \\
\text { (TAAR1) }\end{array}$ & Thyroid epithelial cells & Szumska et al. 2015 \\
\hline Vasopressin receptor 2 (V2R) & Renal epithelial cells & Raychowdhury et al. 2009 \\
\hline
\end{tabular}

causing an efflux of $\mathrm{Cl}^{-}$ions that augments depolarization of the neuron (Kleene 1993; Lowe and Gold 1993; Stephan et al. 2009), which eventually initiates an action potential that propagates along the axon to the olfactory bulb.

$\beta$-Arrestin 2 is recruited to activated ORs to mediate desensitization and receptor internalization at the dendritic knob (Dawson et al. 1993; Mashukova et al. 2006). Interestingly, a nonodorant GPCR has been found to localize to olfactory cilia and modulate OR signaling in mice. Specifically, activation of type 3 muscarinic acetylcholine receptor (M3-R) on the ciliary membrane inhibits the recruitment of $\beta$ - arrestin 2 to ORs, thereby potentiating odorinduced signaling (Fig. 3C) (Jiang et al. 2015). The olfactory epithelium is innervated by nerve endings that release acetylcholine (Baraniuk and Merck 2009). Thus, acetylcholine release may enhance the sensitivity of OR signaling via M3-Rs.

In summary, olfactory cilia possess several critical attributes that optimize OR signaling: (1) They extend into the olfactory epithelium where ORs are exposed to odorants; (2) they allow for enrichment and concentration of the molecular components of the olfactory transduction cascade, thereby optimizing signaling; and (3) they are present in large numbers and 

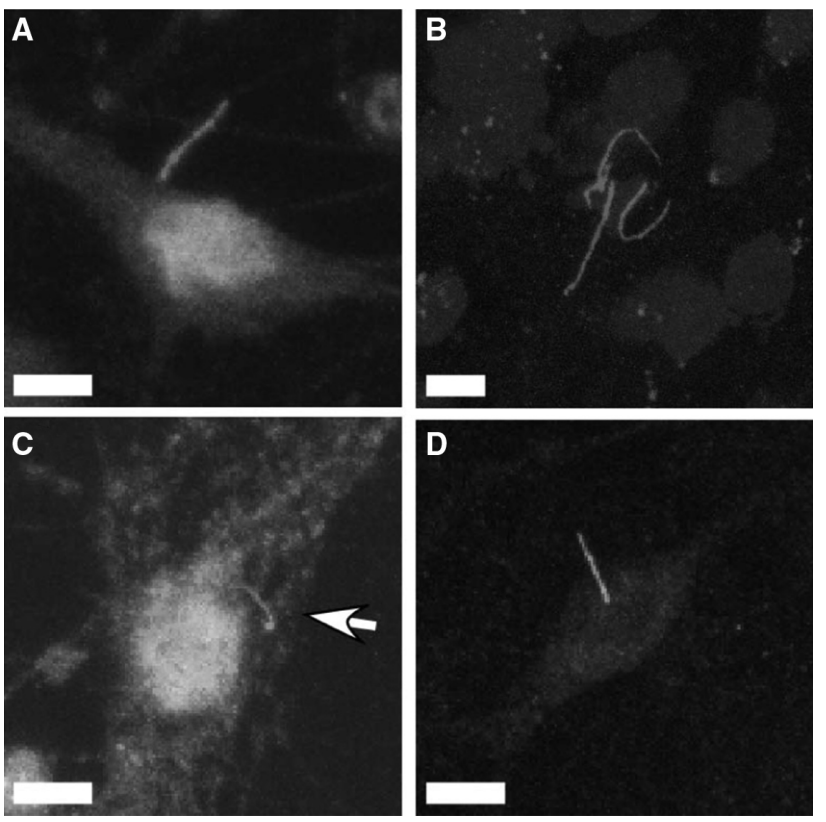

Figure 2. Examples of G-protein-coupled receptors (GPCRs) and effectors that are enriched in primary cilia. (A) Image of a day 7 mouse hippocampal neuron immunolabeled with an antibody to somatostatin receptor subtype 3 (SSTR3) showing an SSTR3-positive cilium projecting from the cell body. (B) Adult mouse brain section corresponding to the medial hypothalamus immunolabeled with an antibody to kisspeptin receptor 1 (KISS1R). Note the presence of multiple KISS1R-positive cilia. (C) Image of a day 7 mouse hippocampal neuron treated with somatostatin and immunolabeled with an antibody to $\beta$-arrestin. Arrow indicates $\beta$ arrestin ciliary localization. (D) Image of a day 7 mouse hippocampal neuron immunolabeled with an antibody to type 3 adenylyl cyclase (AC3) showing an AC3-positive cilium projecting from the cell body. Scale bars, $5 \mu \mathrm{m}$.

have a large surface-to-volume ratio, which increases sensitivity to odorants.

\section{OPSIN SIGNALING}

Vision is initiated when photons are absorbed by the rod and cone photoreceptors in the retina (Arshavsky and Burns 2012). Photoreceptors are highly polarized neurons with a distal end that is comprised of the light-sensing outer segment and a proximal end that synapses on downstream neurons. The outer segment is a highly modified primary cilium packed with membrane disks containing lightsensitive GPCRs and downstream signaling effectors. Upon light activation in rods, rhodopsin activates the $G$ protein transducin, which then stimulates its effector, cGMP phosphodiesterase. This leads to a reduction in intracellular cGMP levels and causes cGMPgated channels to close, thereby hyperpolarizing the cell and generating a transient photoresponse within milliseconds. Rhodopsin kinase then phosphorylates rhodopsin, which leads to visual arrestin binding and a block in transducin activation, thereby terminating the signal. In response to sustained bright light, there is a massive redistribution of phototransduction proteins that involves transducin exiting the rod outer segment and visual arrestin accumulating in the outer segment. This adaptive mechanism plays a role in setting photoreceptor sensitivity and may protect rods from the adverse effects of persistent light exposure (Arshavsky and Burns 2012). Thus, the ciliary outer segment facilitates signaling in response to light and provides a protective mechanism by allowing the physical separation 
K. Mykytyn and C. Askwith
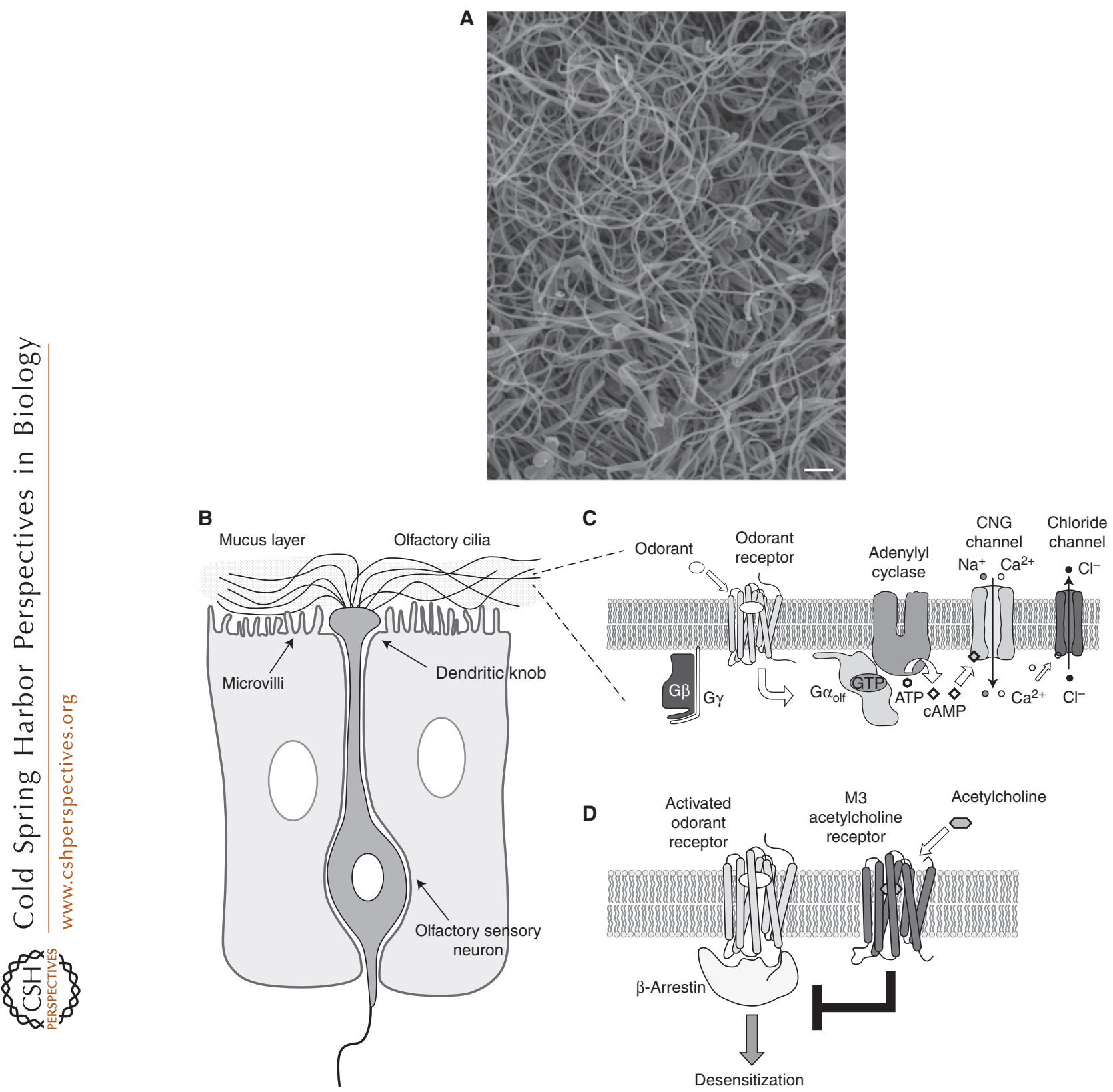

Figure 3. Overview of odorant receptor signaling in olfactory sensory neurons. (A) Scanning electron microscopy image of the surface of the mouse olfactory epithelium. Scale bar, $1 \mu \mathrm{m}$ (courtesy of Jeff Martens). (B) Schematic of a single olfactory sensory neuron with cilia projecting into the olfactory epithelium. $(C)$ Odorant activation of olfactory G-protein-coupled receptors (GPCRs) triggers the activation of the stimulatory G protein $\mathrm{G} \alpha_{\text {olf }}$, which then activates type 3 adenylyl cyclase (AC3) and increases cAMP levels within the cilium. The cAMP binds to and activates cyclic-nucleotide-gated (CNG) channels on the ciliary membrane, leading to an increase in $\mathrm{Ca}^{2+}$ levels, subsequent activation of $\mathrm{Ca}^{2+}$-gated chloride channels, and depolarization of the neuron. (D) $\beta$-Arrestin binding to activated odorant receptors mediates desensitization. The type 3 muscarinic (M3) acetylcholine receptor can inhibit the recruitment of $\beta$-arrestin to odorant receptors, thereby potentiating odor-induced signaling. 
of components of the phototransduction cascade.

\section{GPCR MODULATION OF HEDGEHOG SIGNALING}

Hedgehog (Hh) signaling, which plays an essential role in mammalian development, requires the presence of primary cilia (Huangfu et al. 2003). Briefly, in the absence of Hh ligand, the 12-transmembrane $\mathrm{Hh}$ receptor patched (Ptch1) is enriched on the ciliary membrane and the GPCR Smoothened (Smo) is excluded from the cilium (Rohatgi et al. 2007). In this "OFF" state, cAMP-dependent PKA functions at the base of the cilium to phosphorylate members of the Gli family of transcription factors, which promotes the formation of truncated Gli repressors and inhibits transcription of $\mathrm{Hh}$ target genes (Sasaki et al. 1999; Pan et al. 2006; Tempe et al. 2006; Tuson et al. 2011). Repression of Hh signaling is further enforced by the ciliary GPCR Gpr161. Gpr161 has constitutive activity and couples to $\mathrm{G} \alpha_{\mathrm{s}}$ to increase cellular cAMP levels, thereby increasing activation of PKA (Mukhopadhyay et al. 2013). It is hypothesized that Gpr161 establishes a basal cAMP gradient within the cilium that is important for proper regulation of $\mathrm{Hh}$ signaling. Indeed, disruption of Gpr161 in mouse is embryonic lethal and causes increased Hh signaling in the neural tube (Mukhopadhyay et al. 2013).

In the presence of Hh ligand, Ptch1 and Gpr161 leave the cilium, allowing Smo to enter the cilium, activate Gli transcription factors, and initiate signaling (Corbit et al. 2005; Rohatgi et al. 2007; Mukhopadhyay et al. 2013). Recently, another orphan GPCR, Gpr175, has been shown to localize to cilia in response to Hh treatment and enhances $\mathrm{Hh}$ signaling in several mammalian cell lines (Singh et al. 2015). Specifically, Gpr175 interacts with ciliary $\mathrm{G} \alpha_{\mathrm{i}}$, which leads to a lowering of cAMP levels and an inhibition of PKA activity and Gli repressor formation (Singh et al. 2015). Depletion of Gpr175 in cell lines has a relatively modest effect on signaling ( $\sim 50 \%)$, suggesting that it plays a regulatory role rather than an essential role in $\mathrm{Hh}$ signaling. Indeed, as opposed to
Gpr161 knockout mice, Gpr175 knockout mice are viable and do not have any developmental defects (Singh et al. 2015). The effect of Gpr175 on Hh signaling is dependent on Smo

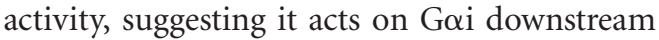
from Smo to modulate PKA activity. Although it does not play an essential role in Hh signaling, it may enhance signaling in certain contexts (Singh et al. 2015).

\section{CILIARY GPCR SIGNALING IN THE RENAL SYSTEM}

A link between renal cilia dysfunction and cystic disease is well established (Cramer and Guay-Woodford 2015). Primary cilia on renal epithelial cells are generally regarded as mechanosensors that illicit $\mathrm{Ca}^{2+}$ signals in response to fluid flow (Fig. 4A). However, there is increasing evidence that renal cilia also mediate GPCR signaling. For example, the type 2 vasopressin receptor (V2R), which regulates $\mathrm{Na}^{+}$and water reabsorption in the mammalian nephron, localizes to cilia on renal epithelial cells (Raychowdhury et al. 2009). In response to vasopressin, ciliary V2R functionally couples with adenylyl cyclase to increase local cAMP concentrations and activate a cation-selective channel (Fig. 4B) (Raychowdhury et al. 2009). These data suggest the presence of a GPCR-mediated cAMP-dependent second-messenger signaling mechanism in renal cilia that regulates intraciliary $\mathrm{Ca}^{2+}$ signals. This signaling, in turn, may modulate different cellular processes, including cell proliferation, ciliary microtubule stability, and/or the ciliary membrane resting potential. Interestingly, renal cAMP levels are increased in numerous animal models of polycystic kidney disease (PKD) (Torres and Harris 2014) and treatment with V2R antagonists inhibits cyst formation (Gattone et al. 2003; Torres et al. 2004). Yet, it is unclear how much V2R signaling within the cilium contributes to these effects.

Dopaminergic signaling in the kidney plays an important role in controlling renal sodium excretion and blood pressure (Carey 2013). Recently, dopamine receptor type 5 (D5) has been localized to cilia on renal epithelial cells (Jin 
A

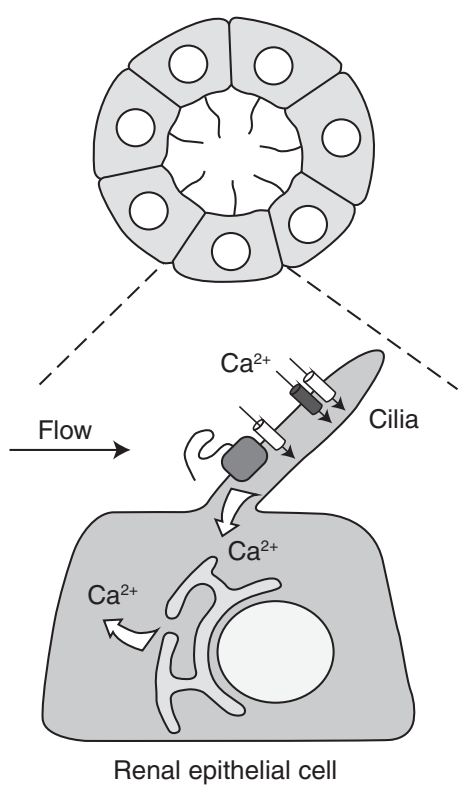

B

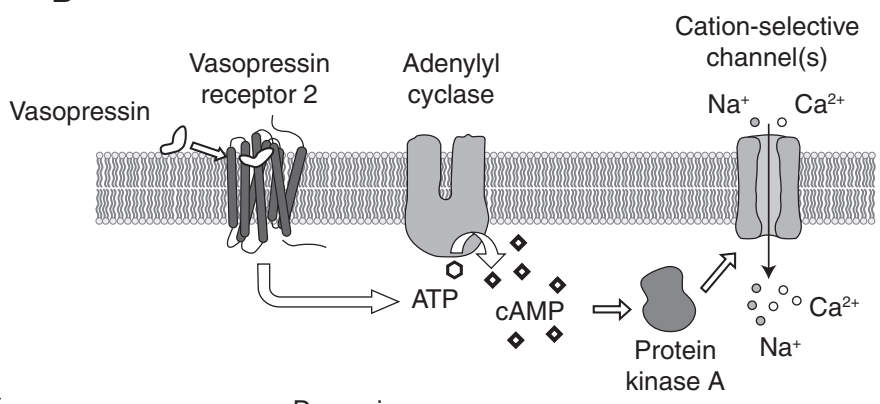

C

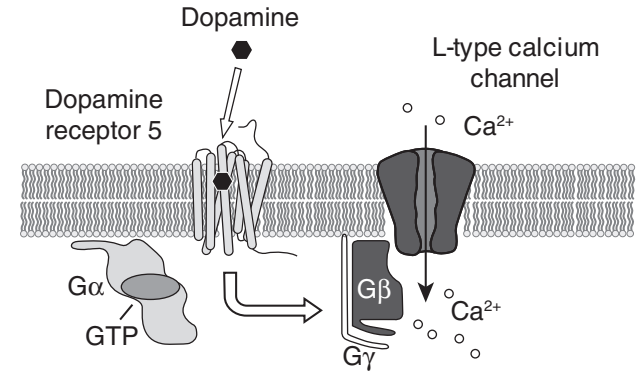

Figure 4. Overview of ciliary signaling in renal cilia. (A) Cross section of a renal tubule showing primary cilia projecting into the lumen of the tubule $(t o p)$. Schematic of flow-induced $\mathrm{Ca}^{2+}$ signaling (bottom). (B) Vasopressin binding to vasopressin receptor 2 (V2R) on the ciliary membrane activates adenylyl cyclase. The increase in local cAMP concentrations activates a cation-selective channel, possibly through protein kinase A, thereby regulating intraciliary $\mathrm{Ca}^{2+}$ signals. $(C)$ Agonist binding to dopamine receptor 5 on the ciliary membrane results in $\mathrm{Ca}_{V} 1.2$ channel activation, possibly through the action of dissociated $\mathrm{G} \beta \gamma$, which increases intraciliary $\mathrm{Ca}^{2+}$ levels.

et al. 2014b; Upadhyay et al. 2014). Evidence for D5-mediated signaling on cilia comes from studies looking at calcium signaling in the ciliary compartment. Specifically, Jin et al. (2014b) used a ciliary-targeted calcium sensor to show that treatment of renal epithelial cells with the D5 agonist fenoldopam causes an increase in calcium levels in the cilium that precedes an increase in calcium levels in the cytosol of the cell. This calcium signal is dependent on the $\mathrm{Ca}_{\mathrm{V}} 1.2 \mathrm{~L}$-type calcium channel, which is localized in the cilium (Jin et al. 2014b). With regard to a functional consequence, fenoldopam treatment also causes an actin-mediated increase in cilia length and increased calcium signaling in response to fluid flow (Upadhyay et al. 2014). Taken together, these results suggest that agonist binding to D5 on the ciliary membrane results in $\mathrm{Ca}_{\mathrm{V}} 1.2$ channel activation, possibly through the action of dissociated $G \beta \gamma$, which increases intraciliary $\mathrm{Ca}^{2+}$ levels (Fig. 4C) (Atkinson et al.
2015). This increased $\mathrm{Ca}^{2+}$ concentration subsequently leads to cilia elongation and confers greater sensitivity to fluid-shear stress. Interestingly, the most frequent target found in a chemical screen of pathways involved in flagellar length control in the unicellular green alga Chlamydomonas was the family of dopamine binding GPCRs (Avasthi et al. 2012). Thus, ciliary dopaminergic signaling may be an evolutionarily conserved mechanism for regulating ciliary length, which may then impact sensitivity to signals.

\section{GPCR SIGNALING IN CHOLANGIOCYTE CILIA}

Cholangiocytes are ciliated epithelial cells that line bile ducts and are responsible for bile acid transport and bicarbonate secretion (Tabibian et al. 2013). Cholangiocyte primary cilia have been determined to be mechano-, chemo-, and 
Ciliary GPCR Signaling

osmosensory organelles that regulate cholangiocyte proliferation (Masyuk et al. 2006, 2008a,b; Gradilone et al. 2007). The importance of these cilia is highlighted by the fact that polycystic liver disease, which is characterized by the development of fluid-filled hepatic cysts arising from cholangiocytes, is associated with ciliopathies (Masyuk et al. 2015). In cholangiocytes, bile acid signaling is transmitted through TGR5, a GPCR that is localized to the apical plasma membrane, subapical compartment, and cilium (Keitel et al. 2009, 2010; Keitel and Haussinger 2011; Keitel and Haussinger 2012; Masyuk et al. 2013). TGR5 is coupled to $G \alpha_{\mathrm{s}}$ and activation of TGR 5 by bile acids causes an increase in intracellular cAMP levels (Maruyama et al. 2002; Kawamata et al. 2003). Downstream effectors of GPCR signaling, including adenylyl cyclase, PKA, and the exchange protein directly activated by cAMP 2 (EPAC-2), have also been localized to cholangiocyte cilia (Masyuk et al. 2006, 2008b). In addition, $G \alpha_{i}$ localizes to the base of cilia on ciliated cholangiocytes. Taken together, these data suggest that cholangiocyte cilia mediate bile acid signaling through TGR5.

Intriguingly, the presence or absence of cilia on cultured cholangiocytes determines the impact of TGR5 agonists (Masyuk et al. 2013). Specifically, agonist treatment of nonciliated cholangiocytes increases colocalization of TGR5 with $\mathrm{G} \alpha_{\mathrm{s}}$ and results in increased cAMP signaling, inhibition of ERK signaling, and increased cellular proliferation. Agonist treatment of ciliated cells, on the other hand, results in increased colocalization of TGR5 with $\mathrm{G}_{\mathrm{i}}$ and decreased cAMP signaling, activation of ERK signaling, and decreased cellular proliferation. Together, these results suggest that TGR5 is functionally coupled to $G \alpha_{s}$ on the plasma membrane and stimulates cellular proliferation in response to bile acid signaling, but is functionally coupled to $\mathrm{G} \alpha_{\mathrm{i}}$ in the cilium to prevent cellular proliferation in response to bile acid signaling. Thus, cholangiocyte cilia provide a compartment for TGR5 to functionally couple with different effectors and provide an alternative signal to TGR5 signaling on the plasma membrane.

\section{CILIARY GPCR SIGNALING ON CENTRAL NEURONS}

Most, if not all, adult neurons in the mammalian brain possess a primary cilium (Handel et al. 1999; Fuchs and Schwark 2004; Bishop et al. 2007). Numerous GPCRs are selectively enriched in neuronal cilia (Table 1). Seminal studies using mouse knockout models have provided compelling evidence for cilia-dependent GPCR signaling in the brain. For example, mice lacking cilia on specific neuronal subpopulations in the brain manifest prominent phenotypes, such as obesity and learning and memory deficits (Davenport et al. 2007; Berbari et al. 2013, 2014). Moreover, mice lacking ciliary GPCRs or ciliary-enriched downstream effectors of GPCR signaling display similar phenotypes (Wang et al. 2009, 2011; Einstein et al. 2010). Together, these results suggest that neuronal cilia provide a unique platform for GPCRs to signal in response to factors in the extracellular milieu. Recent studies have begun to elucidate these signaling pathways and how they impact neuronal function.

Neuropeptide Y (NPY) is one of the most abundant neuropeptides in the mammalian brain and plays an important role in regulating food intake and energy expenditure (Herzog 2003). Recently, two of the NPY receptor subtypes, NPY2R and NPY5R, were found to be enriched in neuronal cilia in mice (Loktev and Jackson 2013). Interestingly, genetically modified mice that are unable to transport NPY2R into neuronal cilia are obese and do not respond to administration of the anorexigenic ligand PYY3-36 (Loktev and Jackson 2013), suggesting that NPY2R ciliary localization is important for ligand-dependent signaling in vivo. In support of this model, quantification of cAMP signaling on RPE cells expressing NPY2R revealed that ligand treatment produced a more pronounced inhibition of cAMP signaling in cells with a cilium (Fig. 5A) (Loktev and Jackson 2013). Thus, cilia localization seemingly enhances NPY2R signaling and may provide a more robust signal to control food intake.

Somatostatin is a widely distributed neurotransmitter and modulator of neural activity 

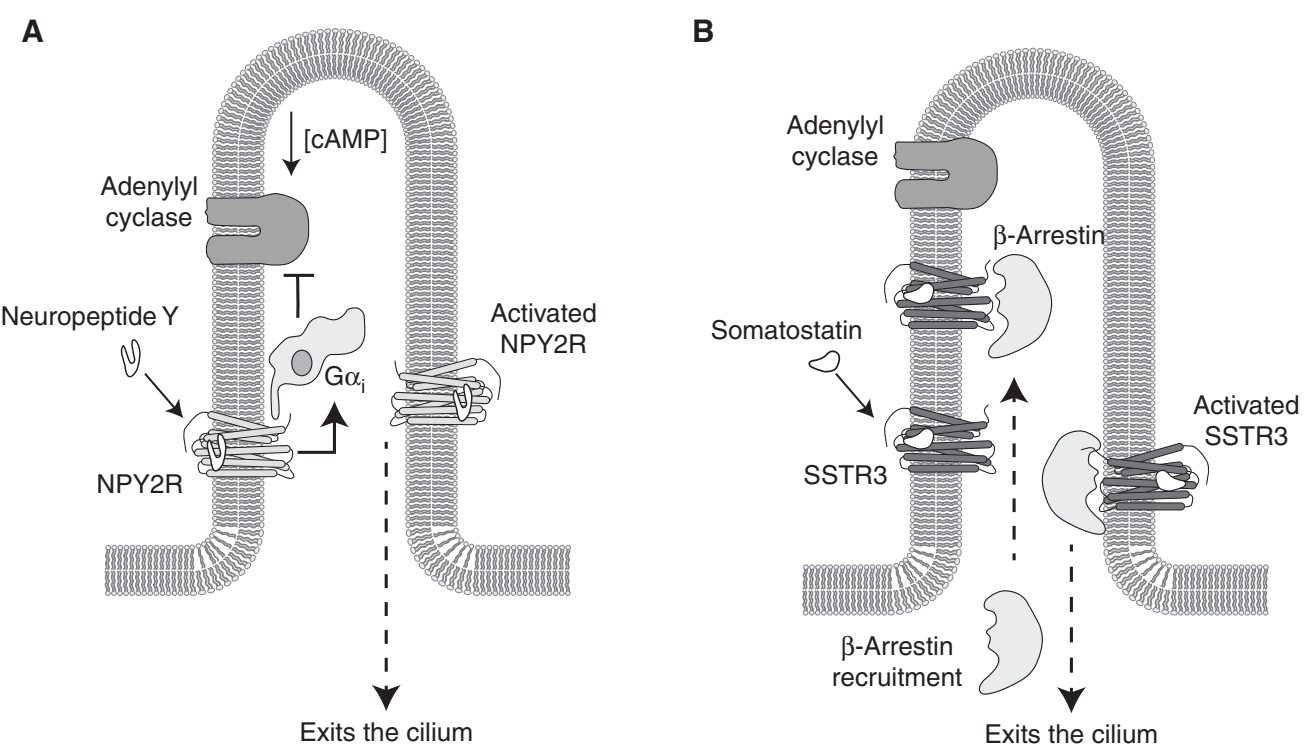

Figure 5. Overview of G-protein-coupled receptor (GPCR) signaling on neuronal cilia. (A) Ligand binding to neuropeptide $\mathrm{Y}$ receptor 2 (NPY2R) on the ciliary membrane may activate $\mathrm{G} \alpha_{\mathrm{i}}$ and inhibit adenylyl cyclase, thereby leading to a reduction in cAMP levels. Ligand treatment also leads to a reduction in NPY2R ciliary localization, suggesting that activated receptor exits the cilium. (B) Somatostatin treatment stimulates endogenous $\beta$-arrestin recruitment into somatostatin receptor subtype 3 (SSTR3)-positive cilia. Somatostatin treatment also causes a $\beta$-arrestin-dependent decrease in SSTR3 ciliary localization, suggesting that $\beta$-arrestin mediates SSTR3 ciliary export.

that can affect many physiological processes, including motor activity and cognitive function (Patel 1999; Barnett 2003; Olias et al. 2004; Viollet et al. 2008). Somatostatin receptor subtype 3 (SSTR3) colocalizes with AC3 in cilia throughout the mouse brain (Handel et al. 1999). Interestingly, mice lacking SSTR3, AC3, or cilia in the hippocampus show similar deficits in learning and memory (Wang et al. 2009; Einstein et al. 2010; Berbari et al. 2014). Together, these results suggest that SSTR3 signals on cilia and this signaling is required for proper learning and memory. In support of this model, it was recently shown that somatostatin treatment stimulates endogenous $\beta$-arrestin recruitment into SSTR3-positive cilia on hippocampal neurons (Green et al. 2016). This recruitment is reminiscent of $\beta$-arrestin translocation to activated GPCRs on the plasma membrane. Furthermore, expressing SSTR3-containing mutations that prevent agonist binding or phosphorylation blocks $\beta$-arrestin recruitment into cilia. These results sug- gest that agonist binds to SSTR3 on the ciliary membrane and leads to phosphorylation of the receptor, which facilitates $\beta$-arrestin ciliary localization (Fig. 5B).

Another finding from this study was that somatostatin treatment causes a rapid $\beta$ arrestin-dependent decrease in the ciliary localization of endogenous SSTR3 (Green et al. 2016). These findings suggest a model whereby activation of SSTR3 on the ciliary membrane stimulates $\beta$-arrestin recruitment, which binds to the receptor and mediates export of SSTR3 from the cilium (Fig. 5B). There are several potential functional consequences of $\beta$-arrestin ciliary recruitment, including (1) SSTR3 desensitization, (2) potentiation of SSTR3 signaling through internalization, and/or (3) $\beta$-arrestinmediated ciliary signaling. Yet, additional studies are required to determine the functional consequences of $\beta$-arrestin recruitment into cilia and whether this is a ubiquitous mechanism for modulating ciliary GPCR signaling on neurons. 
The kisspeptin receptor (KISS1R), which regulates the onset of puberty and adult reproductive function, has recently been found to be enriched in cilia on mouse gonadotropin-releasing hormone $(\mathrm{GnRH})$ neurons (KoemeterCox et al. 2014). Intriguingly, GnRH neurons in adult animals possess multiple KISS1R cilia and the percentage of multiciliated GnRH neurons increases during postnatal development and correlates with sexual maturation. Disruption of $\mathrm{GnRH}$ cilia leads to a significant reduction in kisspeptin-mediated GnRH neuronal activity (Koemeter-Cox et al. 2014), suggesting that cilia enhance KISS1R signaling. More recently, the $\beta 2$-adrenergic receptor ( $\beta 2 \mathrm{AR}$ ) has been shown to be localized to neuronal cilia in the mouse hippocampus (Yao et al. 2015). $\beta 2 \mathrm{AR}$ is activated by noradrenalin and plays a role in hippocampal synaptic plasticity (Hagena et al. 2016). Interestingly, $\beta 2 \mathrm{AR}$ colocalizes in neuronal cilia with the nonselective cation channel polycystic kidney disease 2-like 1 (Pkd2l1). However, $\beta 2 \mathrm{AR}$ ciliary localization is disrupted in mice lacking $\mathrm{Pkd} 211$, suggesting that $\mathrm{Pkd} 211$ is required for $\beta 2 \mathrm{AR}$ ciliary localization (Yao et al. 2015). Pkd2l1 mice have decreased cAMP levels in the brain and increased susceptibility to pentylenetetrazol-induced seizures (Yao et al. $2015)$. As $\beta 2 A R$ is coupled to $G \alpha_{s}$, a potential model is that ciliary localization of $\beta 2 A R$ and Pkd2l1 form a ciliary complex that enhances cAMP production, which inhibits neuronal excitability. Further studies are required to directly test whether KISS1R and $\beta 2 A R$ signal within cilia.

\section{GPCR SIGNALING IN MOTILE CILIA}

The primary function of motile cilia on human airway epithelia is to move mucus out of the lung and their disruption results in airway disease (Fliegauf et al. 2007). Interestingly, several members of the bitter taste receptor (T2R) family have been localized to cilia on human airway epithelia (Shah et al. 2009; Lee et al. 2012). Downstream effectors of the T2R signal transduction pathway include the G-protein $\alpha$-gustducin and the enzyme phospholipase C- $\beta 2$ (PLC- $\beta 2$ ) (Devillier et al. 2015). In ciliated air- way epithelial cells, $\alpha$-gustducin localizes to cilia and PLC- $\beta 2$ localizes to the apical portion of the cell below the cilia (Shah et al. 2009). Application of bitter compounds causes an increase in intracellular calcium concentrations only in ciliated cells, which further results in a $\sim 25 \%$ increase in ciliary beat frequency (Shah et al. 2009). Thus, T2R ciliary localization may facilitate sensing of noxious compounds and generation of a signal that leads to an increase in ciliary activity to eliminate the substance.

\section{POTENTIAL FUNCTIONAL CONSEQUENCES OF CILIA ON GPCR SIGNALING}

A key question is how ciliary localization impacts GPCR signaling. The examples of ciliary GPCR signaling discussed above highlight several general functional consequences cilia can confer on GPCR signaling. First, ciliary localization can enhance GPCR signaling. This may be due to several reasons. Cilia may extend toward the origin of a signal, thereby increasing sensitivity. The cilium may enhance signaling by allowing more efficient coupling of the receptor and its effectors. Note that these two functions are not mutually exclusive. Another possibility is GPCRs generate a unique signal when they are activated on the ciliary membrane versus the plasma membrane. This may be the result of coupling to distinct effectors in the cilium, as in cholangiocyte cilia. As $\beta$-arrestins can function as signal transducers, the finding that endogenous $\beta$-arrestin is recruited into cilia on somatostatin treatment is particularly provocative. This could be analogous to biased agonism, whereby a ligand preferentially triggers G-protein- or $\beta$-arrestin-mediated signaling pathways (Rajagopal et al. 2010). Perhaps activation of a receptor on the ciliary membrane activates $\beta$-arrestin-mediated signaling but not G-protein signaling, or vice versa. Another potential mechanism for generating a unique signal is by facilitating heteromerization of different GPCRs, which can alter ligand binding, Gprotein coupling, and/or desensitization and internalization. There is evidence that SSTR3 and melanin-concentrating hormone receptor 
1 heteromerize in cilia in multiple mouse brain regions (Green et al. 2012). Alternatively, ciliary localization may act as an insulator to prevent GPCR cross regulation (Marley et al. 2013). It is possible that some or all of these mechanisms are used in ciliary GPCR signaling and the precise effects vary between cell types or even between different cells in the same tissue.

\section{CONCLUDING REMARKS}

Given the prevalence of GPCRs as drug targets, understanding ciliary GPCR signaling will likely have important ramifications for therapeutic development. The remaining overarching challenges in the ciliary GPCR field are to identify the complete complement of ciliary GPCRs, define the signaling pathways mediated by ciliary GPCRs and determine how these signaling pathways impact cellular function. Meeting these challenges will require the development of new tools to visualize and/or modulate ciliary GPCR signaling as well as assays to determine how these signals impact cellular function. A better understanding of GPCR signaling will likely yield new therapeutic strategies to targetspecific aspects of GPCR function and lend important insight into the consequences of cilia loss and disruption for human health.

\section{ACKNOWLEDGMENTS}

This work is supported by research project Grant R21 MH107021 from the National Institutes of Health/National Institute of Mental Health (NIH/NIMH) to K.M.

\section{REFERENCES}

Abdul-Majeed S, Nauli SM. 2011. Dopamine receptor type 5 in the primary cilia has dual chemo- and mechano-sensory roles. Hypertension 58: 325-331.

Arshavsky VY, Burns ME. 2012. Photoreceptor signaling: Supporting vision across a wide range of light intensities. J Biol Chem 287: 1620-1626.

Atkinson KF, Kathem SH, Jin X, Muntean BS, Abou-Alaiwi WA, Nauli AM, Nauli SM. 2015. Dopaminergic signaling within the primary cilia in the renovascular system. Front Physiol 6: 103.

Avasthi P, Marley A, Lin H, Gregori-Puigjane E, Shoichet BK, von Zastrow M, Marshall WF. 2012. A chemical screen identifies class a G-protein coupled receptors as regulators of cilia. ACS Chem Biol 7: 911-919.

Bakalyar HA, Reed RR. 1990. Identification of a specialized adenylyl cyclase that may mediate odorant detection. Science 250: 1403-1406.

Baraniuk JN, Merck SJ. 2009. New concepts of neural regulation in human nasal mucosa. Acta Clin Croat 48: $65-73$.

Barnett P. 2003. Somatostatin and somatostatin receptor physiology. Endocrine 20: 255-264.

Berbari NF, Johnson AD, Lewis JS, Askwith CC, Mykytyn K. 2008. Identification of ciliary localization sequences within the third intracellular loop of $\mathrm{G}$ protein-coupled receptors. Mol Biol Cell 19: 1540-1547.

Berbari NF, Pasek RC, Malarkey EB, Yazdi SM, McNair AD, Lewis WR, Nagy TR, Kesterson RA, Yoder BK. 2013. Leptin resistance is a secondary consequence of the obesity in ciliopathy mutant mice. Proc Natl Acad Sci 110: 77967801.

Berbari NF, Malarkey EB, Yazdi SM, McNair AD, Kippe JM, Croyle MJ, Kraft TW, Yoder BK. 2014. Hippocampal and cortical primary cilia are required for aversive memory in mice. PLoS ONE 9: e106576.

Bishop GA, Berbari NF, Lewis JS, Mykytyn K. 2007. Type III adenylyl cyclase localizes to primary cilia throughout the adult mouse brain. J Comp Neurol 505: 562-571.

Brailov I, Bancila M, Brisorgueil MJ, Miquel MC, Hamon M, Verge D. 2000. Localization of 5-HT(6) receptors at the plasma membrane of neuronal cilia in the rat brain. Brain Res 872: 271-275.

Carey RM. 2013. The intrarenal renin-angiotensin and dopaminergic systems: Control of renal sodium excretion and blood pressure. Hypertension 61: 673-680.

Corbit KC, Aanstad P, Singla V, Norman AR, Stainier DY, Reiter JF. 2005. Vertebrate Smoothened functions at the primary cilium. Nature 437: 1018-1021.

Cramer MT, Guay-Woodford LM. 2015. Cystic kidney disease: A primer. Adv Chronic Kidney Dis 22: 297-305.

Davenport JR, Watts AJ, Roper VC, Croyle MJ, van Groen T, Wyss JM, Nagy TR, Kesterson RA, Yoder BK. 2007. Disruption of intraflagellar transport in adult mice leads to obesity and slow-onset cystic kidney disease. Curr Biol 17: 1586-1594.

Dawson TM, Arriza JL, Jaworsky DE, Borisy FF, Attramadal H, Lefkowitz RJ, Ronnett GV. 1993. $\beta$-Adrenergic receptor kinase- 2 and $\beta$-arrestin- 2 as mediators of odorantinduced desensitization. Science 259: 825-829.

DeFea KA. 2011. $\beta$-Arrestins as regulators of signal termination and transduction: How do they determine what to scaffold? Cell Signal 23: 621-629.

Devillier P, Naline E, Grassin-Delyle S. 2015. The pharmacology of bitter taste receptors and their role in human airways. Pharmacol Ther 155: 11-21.

Domire JS, Green JA, Lee KG, Johnson AD, Askwith CC, Mykytyn K. 2011. Dopamine receptor 1 localizes to neuronal cilia in a dynamic process that requires the BardetBiedl syndrome proteins. Cell Mol Life Sci 68: 2951-2960.

Einstein EB, Patterson CA, Hon BJ, Regan KA, Reddi J, Melnikoff DE, Mateer MJ, Schulz S, Johnson BN, Tallent MK. 2010. Somatostatin signaling in neuronal cilia is 
critical for object recognition memory. J Neurosci 30: 4306-4314.

Fliegauf M, Benzing T, Omran H. 2007. When cilia go bad: Cilia defects and ciliopathies. Nat Rev Mol Cell Biol 8: 880-893.

Fuchs JL, Schwark HD. 2004. Neuronal primary cilia: A review. Cell Biol Int 28: 111-118.

Gattone VH II, Wang X, Harris PC, Torres VE. 2003. Inhibition of renal cystic disease development and progression by a vasopressin V2 receptor antagonist. Nat Med 9: 1323-1326.

Gradilone SA, Masyuk AI, Splinter PL, Banales JM, Huang BQ, Tietz PS, Masyuk TV, Larusso NF. 2007. Cholangiocyte cilia express TRPV4 and detect changes in luminal tonicity inducing bicarbonate secretion. Proc Natl Acad Sci 104: 19138-19143.

Green JA, Gu C, Mykytyn K. 2012. Heteromerization of ciliary $\mathrm{G}$ protein-coupled receptors in the mouse brain. PLoS ONE 7: e46304.

Green JA, Schmid CL, Bley E, Monsma PC, Brown A, Bohn LM, Mykytyn K. 2016. Recruitment of $\beta$-arrestin into neuronal cilia modulates somatostatin receptor subtype 3 ciliary localization. Mol Cell Biol 36: 223-235.

Hagena H, Hansen N, Manahan-Vaughan D. 2016. $\beta$-Adrenergic control of hippocampal function: Subserving the choreography of synaptic information storage and memory. Cereb Cortex 26: 1349-1364.

Handel M, Schulz S, Stanarius A, Schreff M, ErdtmannVourliotis M, Schmidt H, Wolf G, Hollt V. 1999. Selective targeting of somatostatin receptor 3 to neuronal cilia. Neuroscience 89: 909-926.

Herzog H. 2003. Neuropeptide Y and energy homeostasis: Insights from Y receptor knockout models. Eur J Pharmacol 480: 21-29.

Hilgendorf KI, Johnson CT, Jackson PK. 2016. The primary cilium as a cellular receiver: Organizing ciliary GPCR signaling. Curr Opin Cell Biol 39: 84-92.

Huangfu D, Liu A, Rakeman AS, Murcia NS, Niswander L, Anderson KV. 2003. Hedgehog signalling in the mouse requires intraflagellar transport proteins. Nature $\mathbf{4 2 6}$ 83-87.

Iannaccone A, Mykytyn K, Persico AM, Searby CC, Baldi A, Jablonski MM, Sheffield VC. 2005. Clinical evidence of decreased olfaction in Bardet-Biedl syndrome caused by a deletion in the BBS4 Gene. Am J Med Genet A 132A: 343-346.

Jenkins PM, McEwen DP, Martens JR. 2009. Olfactory cilia: Linking sensory cilia function and human disease. Chem Senses 34: 451-464.

Jiang Y, Li YR, Tian H, Ma M, Matsunami H. 2015. Muscarinic acetylcholine receptor M3 modulates odorant receptor activity via inhibition of $\beta$-arrestin-2 recruitment. Nat Commun 6: 6448.

Jin D, Ni TT, Sun J, Wan H, Amack JD, Yu G, Fleming J, Chiang C, Li W, Papierniak A, et al. 2014a. Prostaglandin signalling regulates ciliogenesis by modulating intraflagellar transport. Nat Cell Biol 16: 841-851.

Jin X, Mohieldin AM, Muntean BS, Green JA, Shah JV, Mykytyn K, Nauli SM. 2014b. Cilioplasm is a cellular compartment for calcium signaling in response to mechanical and chemical stimuli. Cell Mol Life Sci 71: 2165-2178.

Jones DT, Reed RR. 1989. Golf: An olfactory neuron specific $-\mathrm{G}$ protein involved in odorant signal transduction. Science 244: 790-795.

Kawamata Y, Fujii R, Hosoya M, Harada M, Yoshida H, Miwa M, Fukusumi S, Habata Y, Itoh T, Shintani Y, et al. 2003. A G protein-coupled receptor responsive to bile acids. J Biol Chem 278: 9435-9440.

Keitel V, Haussinger D. 2011. TGR5 in the biliary tree. Dig Dis 29: 45-47.

Keitel V, Haussinger D. 2012. Perspective: TGR5 (Gpbar-1) in liver physiology and disease. Clin Res Hepatol Gastroenterol 36: 412-419.

Keitel V, Cupisti K, Ullmer C, Knoefel WT, Kubitz R, Haussinger D. 2009. The membrane-bound bile acid receptor TGR5 is localized in the epithelium of human gallbladders. Hepatology 50: 861-870.

Keitel V, Ullmer C, Haussinger D. 2010. The membranebound bile acid receptor TGR5 (Gpbar-1) is localized in the primary cilium of cholangiocytes. Biol Chem 391: 785-789.

Kelly E, Bailey CP, Henderson G. 2008. Agonist-selective mechanisms of GPCR desensitization. Br J Pharmacol 153: S379-388.

Kerr DS, Von Dannecker LE, Davalos M, Michaloski JS, Malnic B. 2008. Ric-8B interacts with Goolf and G $\gamma 13$

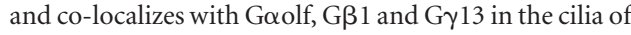
olfactory sensory neurons. Mol Cell Neurosci 38: 341348.

Kleene SJ. 1993. Origin of the chloride current in olfactory transduction. Neuron 11: 123-132.

Koemeter-Cox AI, Sherwood TW, Green JA, Steiner RA, Berbari NF, Yoder BK, Kauffman AS, Monsma PC, Brown A, Askwith CC, et al. 2014. Primary cilia enhance kisspeptin receptor signaling on gonadotropin-releasing hormone neurons. Proc Natl Acad Sci 111: 10335-10340.

Kulaga HM, Leitch CC, Eichers ER, Badano JL, Lesemann A, Hoskins BE, Lupski JR, Beales PL, Reed RR, Katsanis N. 2004. Loss of BBS proteins causes anosmia in humans and defects in olfactory cilia structure and function in the mouse. Nat Genet 36: 994-998.

Lee RJ, Xiong G, Kofonow JM, Chen B, Lysenko A, Jiang P, Abraham V, Doghramji L, Adappa ND, Palmer JN, et al. 2012. T2R38 taste receptor polymorphisms underlie susceptibility to upper respiratory infection. J Clin Invest 122: $4145-4159$.

Li F, Ponissery-Saidu S, Yee KK, Wang H, Chen ML, Iguchi N, Zhang G, Jiang P, Reisert J, Huang L. 2013. Heterotrimeric $\mathrm{G}$ protein subunit $\mathrm{G} \gamma 13$ is critical to olfaction. J Neurosci 33: 7975-7984.

Loktev AV, Jackson PK. 2013. Neuropeptide Y family receptors traffic via the Bardet-Biedl syndrome pathway to signal in neuronal primary cilia. Cell Rep 5: 1316-1329.

Lowe G, Gold GH. 1993. Nonlinear amplification by calcium-dependent chloride channels in olfactory receptor cells. Nature 366: 283-286.

Marchese A, Paing MM, Temple BR, Trejo J. 2008. G proteincoupled receptor sorting to endosomes and lysosomes. Ann Rev Pharmacol Toxicol 48: 601-629. 
Marley A, Choy RW, von Zastrow M. 2013. GPR88 reveals a discrete function of primary cilia as selective insulators of GPCR cross-talk. PLoS ONE 8: e70857.

Maruyama T, Miyamoto Y, Nakamura T, Tamai Y, Okada H, Sugiyama E, Itadani H, Tanaka K. 2002. Identification of membrane-type receptor for bile acids (M-BAR). Biochem Biophys Res Commun 298: 714-719.

Mashukova A, Spehr M, Hatt H, Neuhaus EM. 2006. $\beta$ Arrestin2-mediated internalization of mammalian odorant receptors. J Neurosci 26: 9902-9912.

Masyuk AI, Masyuk TV, Splinter PL, Huang BQ, Stroope AJ, LaRusso NF. 2006. Cholangiocyte cilia detect changes in luminal fluid flow and transmit them into intracellular $\mathrm{Ca}^{2+}$ and cAMP signaling. Gastroenterology 131: 911920.

Masyuk AI, Gradilone SA, Banales JM, Huang BQ, Masyuk TV, Lee SO, Splinter PL, Stroope AJ, Larusso NF. 2008a. Cholangiocyte primary cilia are chemosensory organelles that detect biliary nucleotides via P2Y12 purinergic receptors. Am J Physiol Gastrointest Liver Physiol 295: G725-G734.

Masyuk AI, Masyuk TV, LaRusso NF. 2008b. Cholangiocyte primary cilia in liver health and disease. Dev Dyn 237: 2007-2012.

Masyuk AI, Huang BQ, Radtke BN, Gajdos GB, Splinter PL, Masyuk TV, Gradilone SA, LaRusso NF. 2013. Ciliary subcellular localization of TGR5 determines the cholangiocyte functional response to bile acid signaling. $A m \mathrm{~J}$ Physiol Gastrointest Liver Physiol 304: G1013-G1024.

Masyuk TV, Masyuk AI, LaRusso NF. 2015. TGR5 in the cholangiociliopathies. Dig Dis 33: 420-425.

McEwen DP, Koenekoop RK, Khanna H, Jenkins PM, Lopez I, Swaroop A, Martens JR. 2007. Hypomorphic CEP290/ NPHP6 mutations result in anosmia caused by the selective loss of $\mathrm{G}$ proteins in cilia of olfactory sensory neurons. Proc Natl Acad Sci 104: 15917-15922.

McMahon HT, Boucrot E. 2011. Molecular mechanism and physiological functions of clathrin-mediated endocytosis. Nat Rev Mol Cell Biol 12: 517-533.

Menco BP. 1980. Qualitative and quantitative freeze-fracture studies on olfactory and nasal respiratory epithelial surfaces of frog, ox, rat, and dog. III: Tight-junctions. Cell Tissue Res 211: 361-373.

Menco B. 1992. Ultrastructural studies on membrane, cytoskeletal, mucous, and protective compartments in olfaction. Microsc Res Tech 22: 215-224.

Menco BP. 1997. Ultrastructural aspects of olfactory signaling. Chem Senses 22: 295-311.

Mukhopadhyay S, Wen X, Ratti N, Loktev A, Rangell L, Scales SJ, Jackson PK. 2013. The ciliary G-proteincoupled receptor Gpr161 negatively regulates the Sonic Hedgehog pathway via cAMP signaling. Cell 152: 210 223.

Olias G, Viollet C, Kusserow H, Epelbaum J, Meyerhof W. 2004. Regulation and function of somatostatin receptors. J Neurochem 89: 1057-1091.

Omori Y, Chaya T, Yoshida S, Irie S, Tsujii T, Furukawa T. 2015. Identification of $G$ protein-coupled receptors (GPCRs) in primary cilia and their possible involvement in body weight control. PLOS ONE 10: e0128422.
Pan Y, Bai CB, Joyner AL, Wang B. 2006. Sonic Hedgehog signaling regulates Gli2 transcriptional activity by suppressing its processing and degradation. Mol Cell Biol 26: 3365-3377.

Patel YC. 1999. Somatostatin and its receptor family. Front Neuroendocrinol 20: 157-198.

Rajagopal S, Rajagopal K, Lefkowitz RJ. 2010. Teaching old receptors new tricks: Biasing seven-transmembrane receptors. Nat Rev Drug Discov 9: 373-386.

Rask-Andersen M, Almen MS, Schioth HB. 2011. Trends in the exploitation of novel drug targets. Nat Rev Drug Discov 10: 579-590.

Raychowdhury MK, Ramos AJ, Zhang P, McLaughin M, Dai XQ, Chen XZ, Montalbetti N, Del Rocio Cantero M, Ausiello DA, Cantiello HF. 2009. Vasopressin receptormediated functional signaling pathway in primary cilia of renal epithelial cells. Am J Physiol Renal Physiol 296: F87-97.

Ressler KJ, Sullivan SL, Buck LB. 1993. A zonal organization of odorant receptor gene expression in the olfactory epithelium. Cell 73: 597-609.

Rohatgi R, Milenkovic L, Scott MP. 2007. Patched1 regulates hedgehog signaling at the primary cilium. Science 317 : 372-376.

Sasaki H, Nishizaki Y, Hui C, Nakafuku M, Kondoh H. 1999. Regulation of Gli2 and Gli3 activities by an amino-terminal repression domain: Implication of Gli2 and Gli3 as primary mediators of Shh signaling. Development 126: 3915-3924.

Shah AS, Ben-Shahar Y, Moninger TO, Kline JN, Welsh MJ. 2009. Motile cilia of human airway epithelia are chemosensory. Science 325: 1131-1134.

Shenoy SK, Lefkowitz RJ. 2011. $\beta$-Arrestin-mediated receptor trafficking and signal transduction. Trends Pharmacol Sci 32: 521-533.

Shukla AK, Xiao K, Lefkowitz RJ. 2011. Emerging paradigms of $\beta$-arrestin-dependent seven transmembrane receptor signaling. Trends Biochem Sci 36: 457469.

Singh J, Wen X, Scales SJ. 2015. The orphan G proteincoupled receptor Gpr175 (Tpra40) enhances Hedgehog signaling by modulating cAMP levels. J Biol Chem 290: 29663-29675.

Sorkin A, von Zastrow M. 2009. Endocytosis and signalling: Intertwining molecular networks. Nat Rev Mol Cell Biol 10: 609-622.

Stephan AB, Shum EY, Hirsh S, Cygnar KD, Reisert J, Zhao H. 2009. ANO2 is the cilial calcium-activated chloride channel that may mediate olfactory amplification. Proc Natl Acad Sci 106: 11776-11781.

Szumska J, Qatato M, Rehders M, Fuhrer D, Biebermann H, Grandy DK, Kohrle J, Brix K. 2015. Trace amine-associated receptor 1 localization at the apical plasma membrane domain of fisher rat thyroid epithelial cells is confined to cilia. Eur Thyroid J 4: $30-41$.

Tabibian JH, Masyuk AI, Masyuk TV, O’Hara SP, LaRusso NF. 2013. Physiology of cholangiocytes. Compr Physiol 3: 541-565. 
Takeda S, Kadowaki S, Haga T, Takaesu H, Mitaku S. 2002. Identification of $\mathrm{G}$ protein-coupled receptor genes from the human genome sequence. FEBS Lett 520: 97-101.

Tang XL, Wang Y, Li DL, Luo J, Liu MY. 2012. Orphan G protein-coupled receptors (GPCRs): Biological functions and potential drug targets. Acta Pharmacol Sin 33 363-371.

Tempe D, Casas M, Karaz S, Blanchet-Tournier MF, Concordet JP. 2006. Multisite protein kinase A and glycogen synthase kinase $3 \beta$ phosphorylation leads to Gli3 ubiquitination by $\mathrm{SCF}^{\beta \mathrm{TrCP}}$. Mol Cell Biol 26: $4316-4326$

Torres VE, Harris PC. 2014. Strategies targeting cAMP signaling in the treatment of polycystic kidney disease. J Am Soc Nephrol 25: 18-32.

Torres VE, Wang X, Qian Q, Somlo S, Harris PC, Gattone VH II. 2004. Effective treatment of an orthologous model of autosomal dominant polycystic kidney disease. Nat Med 10: 363-364.

Tuson M, He M, Anderson KV. 2011. Protein kinase A acts at the basal body of the primary cilium to prevent Gli2 activation and ventralization of the mouse neural tube. Development 138: 4921-4930.
Upadhyay VS, Muntean BS, Kathem SH, Hwang JJ, Aboualaiwi WA, Nauli SM. 2014. Roles of dopamine receptor on chemosensory and mechanosensory primary cilia in renal epithelial cells. Front Physio 5: 72.

Vassar R, Ngai J, Axel R. 1993. Spatial segregation of odorant receptor expression in the mammalian olfactory epithelium. Cell 74: 309-318.

Viollet C, Lepousez G, Loudes C, Videau C, Simon A Epelbaum J. 2008. Somatostatinergic systems in brain: Networks and functions. Mol Cell Endocrinol 286: $75-87$.

Wang Z, Li V, Chan GC, Phan T, Nudelman AS, Xia Z, Storm DR. 2009. Adult type 3 adenylyl cyclase-deficient mice are obese. PLoS ONE 4: e6979.

Wang Z, Phan T, Storm DR. 2011. The type 3 adenylyl cyclase is required for novel object learning and extinction of contextual memory: Role of cAMP signaling in primary cilia. J Neurosci 31: 5557-5561.

Yao G, Luo C, Harvey M, Wu M, Schreiber TH, Du Y, Basora N, Su X, Contreras D, Zhou J. 2015. Disruption of polycystin-L causes hippocampal and thalamocortical hyperexcitability. Hum Mol Genet 25: 448-458. 


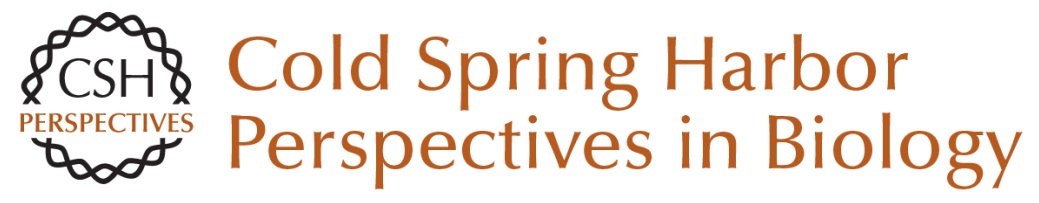

\section{G-Protein-Coupled Receptor Signaling in Cilia}

Kirk Mykytyn and Candice Askwith

Cold Spring Harb Perspect Biol 2017; doi: 10.1101/cshperspect.a028183 originally published online February 3, 2017

\section{Subject Collection Cilia}

Ciliary Mechanisms of Cyst Formation in

Polycystic Kidney Disease

Ming Ma, Anna-Rachel Gallagher and Stefan Somlo

Photoreceptor Cilia and Retinal Ciliopathies Kinga M. Bujakowska, Qin Liu and Eric A. Pierce

G-Protein-Coupled Receptor Signaling in Cilia Kirk Mykytyn and Candice Askwith

Evolution of Cilia David R. Mitchell

Transition Zone Migration: A Mechanism for Cytoplasmic Ciliogenesis and Postaxonemal Centriole Elongation

Tomer Avidor-Reiss, Andrew Ha and Marcus L. Basiri

Cilia and Obesity

Christian Vaisse, Jeremy F. Reiter and Nicolas F. Berbari

Posttranslational Modifications of Tubulin and Cilia

Dorota Wloga, Ewa Joachimiak, Panagiota Louka, et al.
Cilia in Left-Right Symmetry Breaking Kyosuke Shinohara and Hiroshi Hamada

Discovery, Diagnosis, and Etiology of Craniofacial Ciliopathies Elizabeth N. Schock and Samantha A. Brugmann

Axoneme Structure from Motile Cilia Takashi Ishikawa

Cilia and Ciliopathies in Congenital Heart Disease Nikolai T. Klena, Brian C. Gibbs and Cecilia W. Lo

Sperm Sensory Signaling Dagmar Wachten, Jan F. Jikeli and U. Benjamin Kaupp

\section{Primary Cilia and Coordination of Receptor} Tyrosine Kinase (RTK) and Transforming Growth Factor $\beta$ (TGF- $\beta$ ) Signaling Søren T. Christensen, Stine K. Morthorst, Johanne B. Mogensen, et al.

Primary Cilia and Mammalian Hedgehog Signaling Fiona Bangs and Kathryn V. Anderson

For additional articles in this collection, see http://cshperspectives.cshlp.org/cgi/collection/

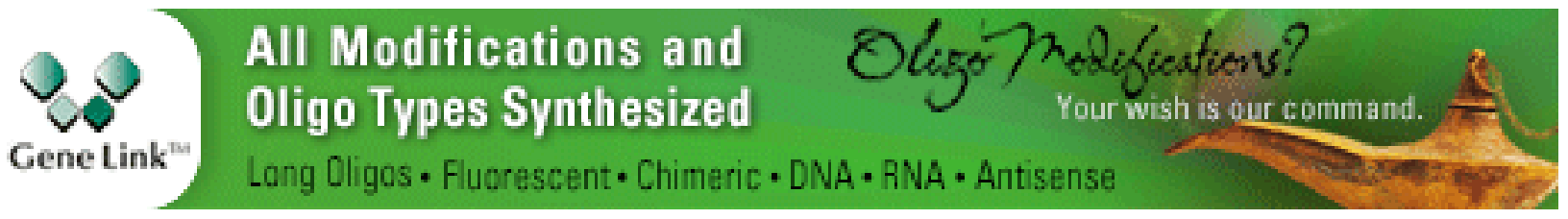


Radial Spokes--A Snapshot of the Motility Regulation, Assembly, and Evolution of Cilia and Flagella

Xiaoyan Zhu, Yi Liu and Pinfen Yang
Cilia and Mucociliary Clearance

Ximena M. Bustamante-Marin and Lawrence E. Ostrowski

For additional articles in this collection, see http://cshperspectives.cshlp.org/cgi/collection/

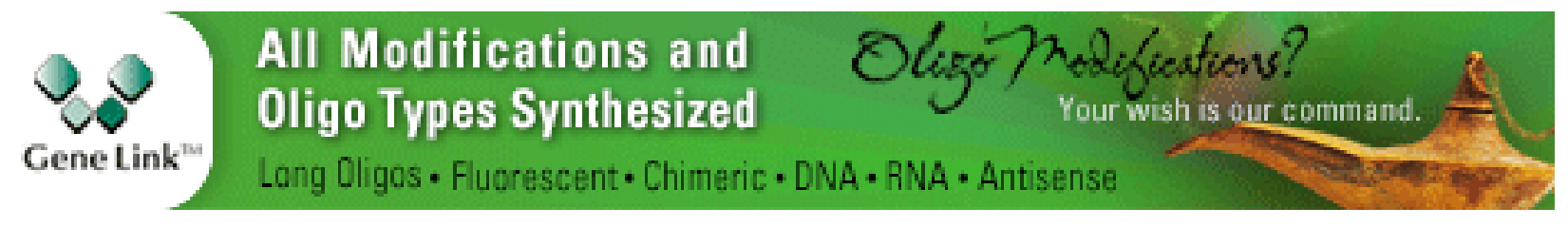

Copyright @ 2017 Cold Spring Harbor Laboratory Press; all rights reserved 